
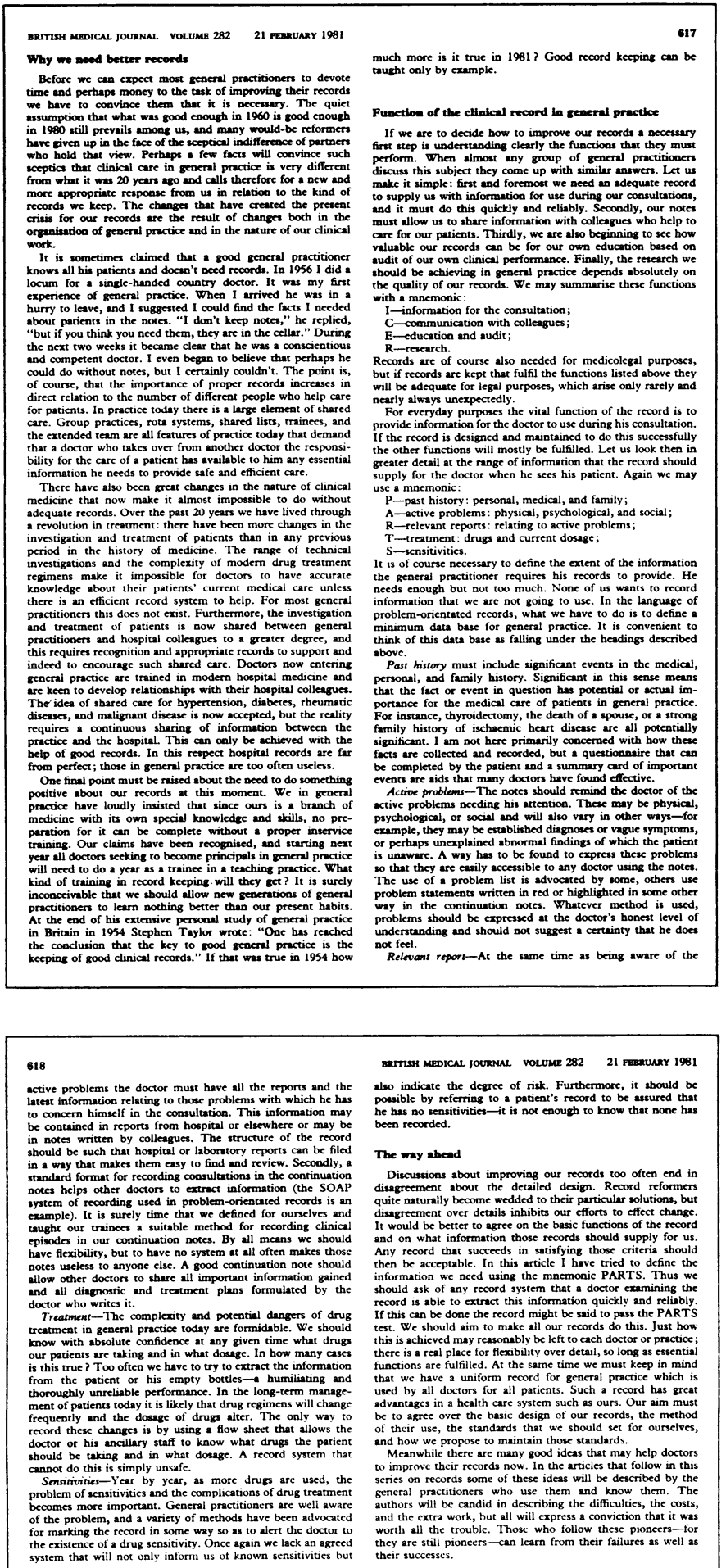

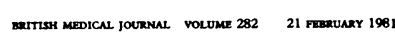
also indicare the degree of risk. Furchermore, it should be
possible by referring to 2 patican's record to be sssured that The way abead

Discussions about improving our records too often end in
divegreement about the detailed design. Record reformers diagereement about the detailed design. Record reformers
quite naturally become wedded to their particular solutions, but

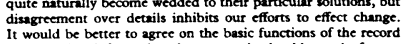
Any record that succeeds in satisfying those criteria should

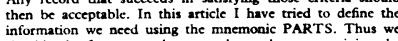
information we need using the mnemonic PARTS. Thus wh
should ask of any record system that a doctor examining the

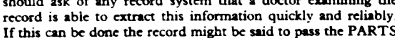
If this can be done the record might be seid to pass the PARTS
test. We should aim to make ail our trecords do this. Just how

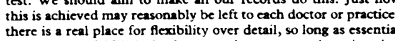
functions are fulfilied. At the same time we must kecp in min
that we have aniform record for general practice which
used by all doctors for all patients. Such a record has gree adve to agrese over che chase desesign of our records, the method
of thcir use, the standards that we should set for ourselves, and how we propose to maintain those standards.
Meanwhile there are many good ideas that may help doctors Mcanwhile there are many good ideas that may help docto
to improve their records now. In the carticles that follow in this
siries on records scries on records some of thesc ideas will be described by the
gencral practitioners who use them and know them. The gencral practitioners who use them and know them. The
authors will be candid in describing the difficultecs, the costs,

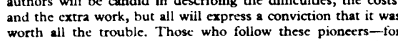
they are still pioncers-can learn from their failures as well as

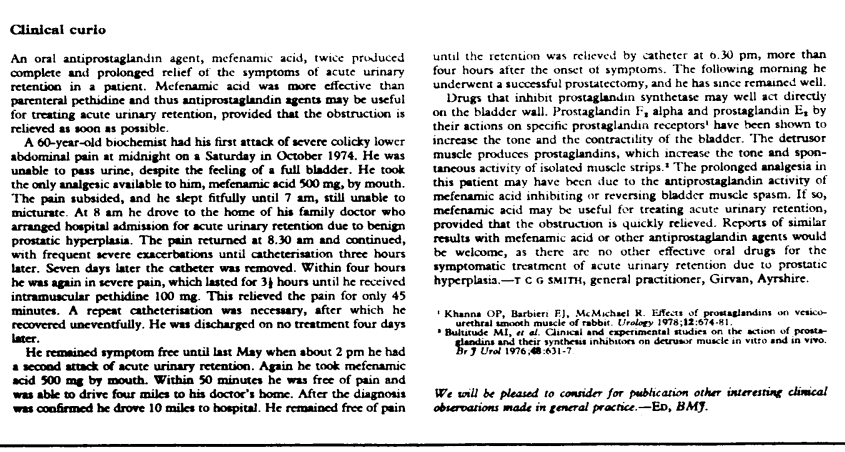

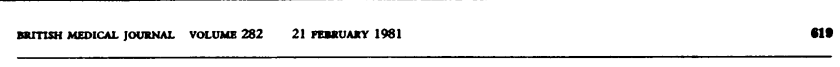

\title{
Pitfalls in Practice
}

\section{Situation vacant}

I: Hiring a receptionist

JOHN OLDROYD

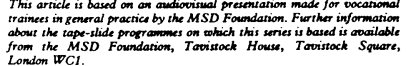

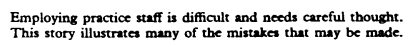

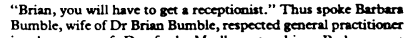

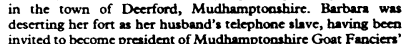

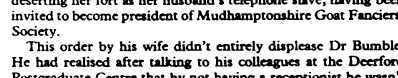

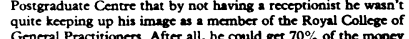

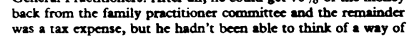

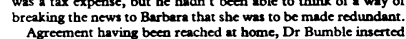

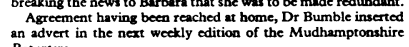

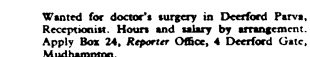

Two days after its publication, Dr Bumble received 2 reply
in the surgery letter-box.

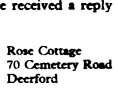

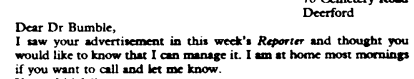

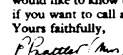

Priment

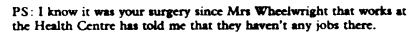

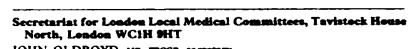

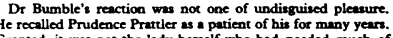

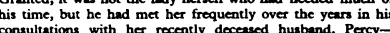

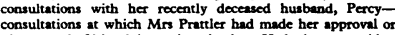

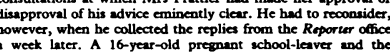

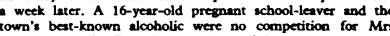

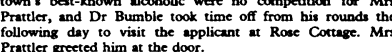

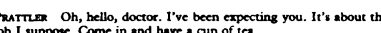

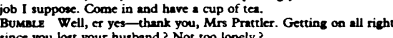

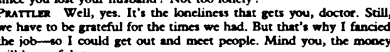

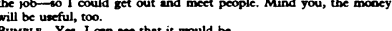

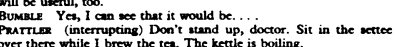

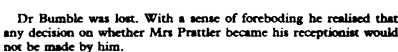

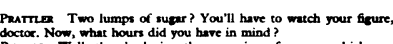

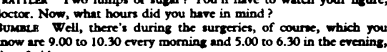

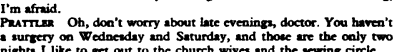

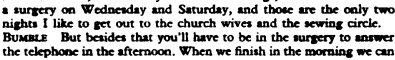

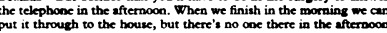

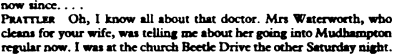

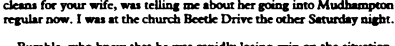
Bumble, who knew that he
fect he must te more efficent.

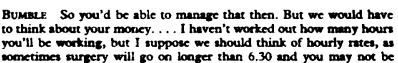

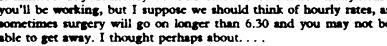

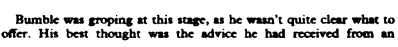

$\infty$

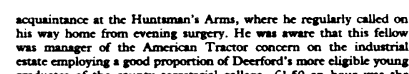

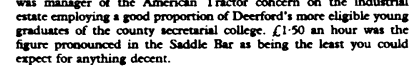
Busarex 61.45 an hour.

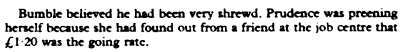

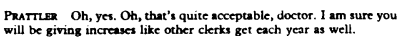

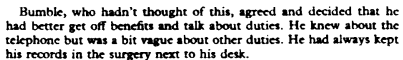

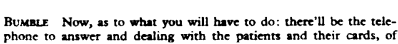

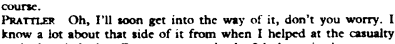

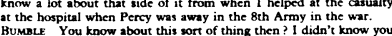

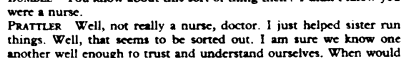

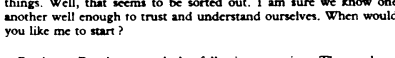

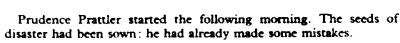

Mistakes he made

(1) Dr Bumble lacked preparation because he failed to assess his needs.
(2) Ihe adver was unsuitatele becausse it was not specific.
(3) It was probably y unwise to appoint a patient of the practice is his receppionist.
(4) He should have waited longer for replics or inded madc

Clinical Curio

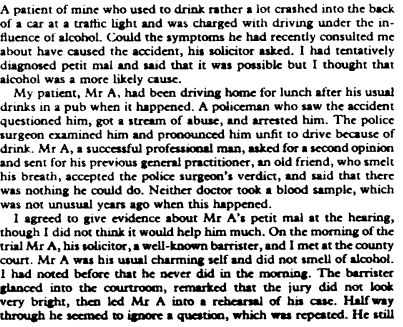

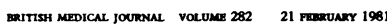
inquiries from other rources such as the recreterial oollege, ocher
medical staff training agencies, and the job centre.

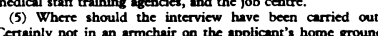

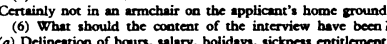

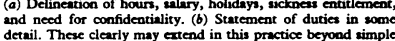

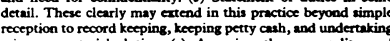

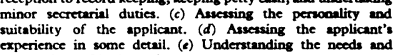

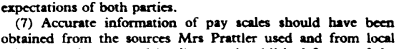

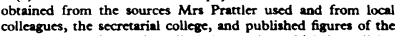
Whitley Solte Givild of Medical Secreterises, which is sviliable

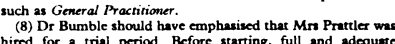

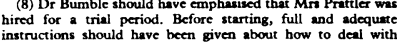

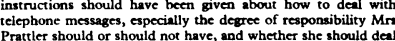
with these on her own.
(9) The conversation sugersts that no contract of employment

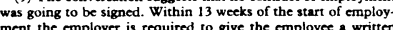

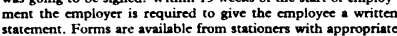

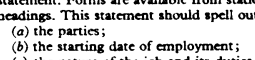

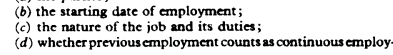

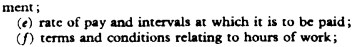

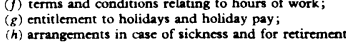
(h) arrangements in case of sickness and for retirementi
(i) length of nouice to be given on either side ir (Employment Protection Act 1978; Section $t$ ) In the next article 1 will show how Dr Bumble got into
difficultics and how he could have avoided them.

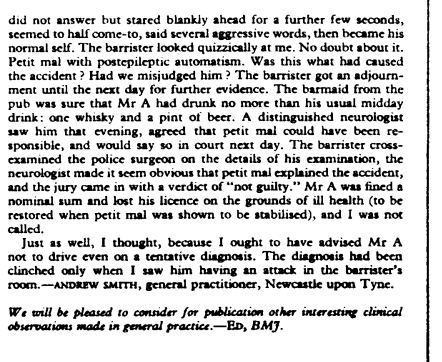

